\title{
An Indigenous Language Model for Innovation and Technology Transfer in Agriculture
}

\author{
Emily Ayieta Ondondo \\ Department of Linguistics, Languages and Literature, School of Humanities and Social Sciences, Jaramogi Oginga Odinga University of \\ Science and Technology (JOOUST), Bondo, Kenya
}

Email address:

eondondo@gmail.com

To cite this article:

Emily Ayieta Ondondo. An Indigenous Language Model for Innovation and Technology Transfer in Agriculture. International Journal of Applied Linguistics and Translation. Vol. 6, No. 2, 2020, pp. 52-58. doi: 10.11648/j.ijalt.20200602.13

Received: April; 29, 2020; Accepted: May 20, 2020; Published: May 29, 2020

\begin{abstract}
Sustainable agriculture requires effective communication of new innovations and technologies in the field to the people at the grass roots. Effective communication occurs through a language that the communicants understand best. Language is part of culture and culture as a way of people's life encompasses beliefs, taboos and attitudes. These aspects affect how people perceive, internalize, react to and embrace issues, innovation and technology issues included. Information pertaining agricultural issues in Kenya is passed down to the people at the grassroots predominantly through English and Kiswahili. However, majority of the people engaging in agricultural activities at the grassroots use indigenous languages as their main language of interaction. Indigenous languages are the most effective engines of peoples' cultures and self-identification forming cultural legacies through which all forms of human interaction are embraced. This then implies that indigenous languages have a key role to play in achieving the nation's agricultural goals. Nonetheless, the importance of these languages in the agricultural process has been relatively neglected, compromising the achievement of sustainable agriculture. Adopting a descriptive design, this study demonstrates how indigenous languages relate to the transfer of innovation and technology for sustainable agriculture in Kenya. It further suggests a model for the incorporation of indigenous languages into the agricultural process, in Kenya, for sustainability.
\end{abstract}

Keywords: Indigenous Language, Innovation, Technology, Sustainable Agriculture Model

\section{Introduction}

The achievement of sustainable agricultural in Kenya is a dream yet to be achieved. This is demonstrated by the fact that one of the four main agenda that the Kenyan nation seeks to achieve is food security. Food security, in Kenya, can only be reached through sustainable agriculture. Sustainable agriculture requires the adoption and embracement of new innovations and technologies, which emerge every now and then in the field. New innovations and technologies are meant to facilitate good and improved practices in the field of agriculture, with better results [1]. Therefore, all stakeholders in the agricultural framework, in the sector, endeavor to communicate any new innovations and technologies to the people at all levels in the line of agricultural production. If sustainable agriculture is to be realized, effective communication of new innovations and technologies in the agricultural sector to the people involved in agricultural activities at all levels is paramount. Effective communication occurs through a language that the communicants understand best [2-4]. Given that language is the primary form through which messages (whether spoken or written) are expressed in communication [5], language is central and vital to communication. This has the implication that the language used in any communication process would have an impact on effective communication of the messages. In the agricultural sector in Kenya, communication predominantly occurs through the use of English and/or Kiswahili and rarely through indigenous languages, despite the fact that many of the people involved in agricultural production in Kenya predominantly use indigenous languages in their day today agricultural activities. The question that arises that this study sought to address is could the language used in the communication process in agricultural activities be the reason as to why sustainable agriculture has not been attained in Kenya? Specifically, the 
study argues that the use of indigenous languages in communicating information pertaining to agriculture to the people concerned would foster effective communication of such information leading to the achievement of sustainable agriculture in Kenya. The study then suggests a model for incorporating indigenous languages into the transfer of innovations and technologies to the people involved in agricultural activities in Kenya for sustainable agriculture and food security.

\section{Innovation and Technology in Sustainable Agriculture}

Agriculture, world over, has undergone tremendous transformations. Farming has become both more efficient and more sustainable. This is attributed to agricultural innovations, experiences and technologies that have occurred in agriculture over time and that have changed agricultural work [6]. The changes have, in turn, affected the lives of the communities involved. Currently, there is a wide new range of innovations and technologies in agriculture. There are many ways to grow and produce food and so much to learn about the science of growing crops and raring animals. Modern farming is, therefore, full of opportunities for better and more effective agricultural production [7].

A lot of innovations are witnessed in the mobile/information technology and energy spaces that have the potential to make a huge impact on the farm. For example, smart power systems, precision agriculture tools, farm management software, and affordable sensors are available and are within reach of even the smallest farmers today [7]. Mechanical innovations such as tractors, irrigation systems, harvesting, planting, weeding and threshing machines cannot be left out either. If all the new innovations and technologies in agriculture are deployed effectively, they can work towards achieving long-term agricultural objectives such as efficient farm management and resource efficiency, supply chain efficiency and traceability [8].

Efficient farm management would enable the production of enough food for growing populations, in the advent of declining percentage of farmers. On the other hand, a whole farm approach coupled with precision agriculture technologies would optimize the farmer's efficiency through optimal fertilizer application, effective use of water, soil, energy etc. This would enhance time and money saving, creation of more productive fields, cutting down on production costs and improving profit margins. Supply chain efficiency would ensure that the food produced is not wasted at the consumption stage or before it even reaches the consumer as is the case in African countries as a whole and Kenya specifically. Traceability tools and processes would enable the management and monitoring of the flow of agricultural inputs. This would improve efficiency, product differentiation, food safety, and product quality. In addition, traceability and transparency in the food supply would benefit the farmer in the long run, by opening up opportunities to access credit and markets. Overall then, new innovations and technology in agriculture have a lot of benefits that could lead to sustainable agriculture in any country.

\section{Sustainable Agriculture in Kenya}

Sustainable agriculture in Kenya is vital for food security. Food security is a priority for Kenya, as a nation, evidenced by the fact that one of the four main development agenda for Kenya is the achievement of food security and nutrition. Food is an important aspect in nutrition.

Sustainable agriculture is farming that meets a society's food needs in the present without compromising the ability of future generations to meet their own needs [9]. It is a long-term methodological structure that incorporates profit, environmental stewardship, fairness, health, business and familial aspects on a farm setting. It is defined by 3 integral aspects which are: economic profit, environmental stewardship and social responsibility. Consequently, sustainable agriculture is not only an economic concept but also encompasses education and mass participation in agricultural activities [9].

For a continuous vibrant agricultural sector in which many people are involved and participate in agricultural activities, economic gain is the driving force. For economic gain to be achieved and witnessed, education of the masses on the innovations, technologies and all information that appertain such a sector becomes imperative. It is through the appreciation and application of this knowledge to all agricultural activities at all stages in the whole process that leads to the economic gains. Therefore, sustainable agriculture is the aggregate financial buoyancy as well as the education of and involvement of the citizenry in activities that will lead to the nourishing of a country's agricultural sector. It is all of these things that aid the development of any nation's agricultural sector, both overtly and covertly.

The masses that need to participate in agricultural activities and to whom agricultural information is to be passed to, in Kenya, live in the rural areas. They belong to specific ethnic communities and mainly use their indigenous languages for communication. These rural communities also have indigenous knowledge and culture specific to them, aspects which are expressed through their local indigenous languages. Indigenous knowledge and culture can play a key role in the design of sustainable agricultural systems, increasing the likelihood that rural populations will accept, develop, and maintain agricultural innovations, technologies and interventions [10].

\section{Communication, Language and Sustainable Agriculture}

Understanding communication and how it works is important to human beings. This is because everyday activities and functions involve some form of direct or indirect 
communication. Regardless of the activity or function, the participants in a communication event communicate with and through other participants. As a result, every participant's communication skills affect the effectiveness of any communication event $[11,12]$. It, therefore, seems reasonable to argue that one of the most inhibiting forces to the effectiveness of any communication event is a lack of effective communication [13] and that good communication skills are important to ones success as a participant in a communication event.

Human communication, however, is faced with a lot of problems and difficulties [9]. Misinterpretations and misunderstandings arise more often than not. This is because whenever people try to communicate, something often seems to get in the way and they are not understood in the way they intended. Even when there is understanding it is often hard to get people to think or behave the way one would wish them to and this is largely dependent on the objective of the communication. For communication to be effective a message must be received (heard or read), understood, accepted and acted upon (change behavior or attitude). If this does not happen communication has failed and participants in a communication event get frustrated and resentful $[9,14]$.

Language is essentially a means of communication among the members of a society [15]. In the expression of culture, language is a fundamental aspect. It is the tool that conveys traditions and values related to group identity [16]. As a tool of communication among the members of a society, language is influenced by the very society where it functions. Moreover, being the most significant tool of communication, a particular language which is mastered only by some people has often been the determining factor in turning these people into a separate group as a people, a nation or a state. The distinction between nations mainly traces the geographical distribution in space of the pertaining languages while the linguistic community, that is, the fact that they all use the same language, is the essentially defining element for economical and political communities. As a system, language is, therefore, a general, abstract aspect and a sum of organization skills and principles that governs any concrete act of communication and acts as a means of communication.

Difference in language is the most obvious barrier to communication as two people speaking two different languages differ in their linguistic ability and can thus not communicate with each other $[9,17,18]$. For instance, when an agricultural officer who does not speak or understand Dholuo goes to Asembo in Bondo where most people do not speak or understand English but Dholuo, there will be a communication breakdown resulting from differences in language and linguistic ability. In other cases, even when people speak the same language, some people may have low vocabulary whereas some may have very high vocabulary attributed to their linguistic ability in the language, literacy status and level of education. Vocabulary may also be less if a person uses the language as their unofficial language. If a person with high vocabulary and linguistic ability talks with another with low ability, the latter person will not understand the words used leading to miscommunication of the whole message.

The message that is to be communicated occurs as a thought in the mind of the sender. This thought has to be converted into an expressible form (code), that is, words and/or gestures [14, 19]. Words constitute language, which is a code that can only be understood if both parties give the same meaning to the symbols that are used. Language is stored in the brain of human beings in form of lexical items and rules that determine how these items structure and function. Language, thought and culture are intertwined in the sense that thoughts and culture are expressed through language [15-16, 19-23]. To produce real speech or writing, lexical items are retrieved from the brain and structured according to language specific rules and culture. In this way language, thought and culture are interrelated because they have to work together as a system in the production of speech or writing.

Therefore, for communication to be effective there is need to use a language that both parties understand factoring in the linguistic ability of the communicants in the language, the amount of vocabulary they share and their culture [2-4]. In this case, in Kenya, the best language to be used for communicating agricultural innovations and technologies to the people concerned should be their native languages as these are the languages that they know, have high linguistic abilities in, understand best, identify with and express their culture.

\section{Indigenous Knowledge and Sustainable Agriculture}

Indigenous knowledge can play a key role in the design of sustainable agricultural systems, increasing the likelihood that rural populations will accept, develop, and maintain innovations and interventions [9]. Indigenous knowledge is stored, carried in and transmitted through indigenous languages. Indigenous knowledge can be defined as the sum of experience and knowledge of a given ethnic group that forms the basis for decision-making in the face of familiar and unfamiliar problems and challenges [24-26]. Indigenous communities in Kenya, who constitute the masses that participate in agricultural activities, have their own sophisticated ways of looking at the world. They have names for many different kinds of plants, ways to diagnose and treat plant and animal diseases, and methods to crop fertile and infertile soils. This knowledge has accrued over many centuries, and is a critical and substantial aspect of the culture and technology of any society. Yet, in the Kenyan context and the African context as a whole, this knowledge has often been overlooked by Western scientific research and development and the stakeholders in the agricultural process in Kenya.

Indigenous knowledge functions within the given socio-economic and spatial boundaries of the society and plays an active part in the culture of the population concerned, being preserved, communicated, and used by its members to 
serve some purpose in relation to productive activity within the society [27]. It can be transferred by quite elaborate systems, often involving oral transmission using stories and myths. Yet few examples have been methodically recorded, and fewer still have been studied with the purpose of developing an integrated approach to solving agricultural and rural problems [28].

Indigenous knowledge packaged in indigenous languages is important in agriculture because many innovative and technological solutions that have been proposed to address problems in rural communities have failed in the field because they do not take into account the local culture, particularly society's preferences, beliefs, attitudes, taboos, skills, and knowledge. Success in attaining sustainable agriculture is more likely to be achieved when local people are involved in the planning and implementation of agricultural innovations and technologies. Officials who are familiar with indigenous knowledge and languages are, therefore, better equipped to facilitate participation by the local populations.

Nonetheless, indigenous communities around the world are constantly struggling to maintain their languages, their traditions and their knowledge, in a system still dominated by a western worldview. They face the challenge of living in two worlds, the indigenous and the non-indigenous one, in constant tension with each other, with the latter having more power in shaping the former. This results in indigenous populations having their language, traditions and knowledge being eclipsed by western knowledge, imposed on them through western institutions. Imposition leads to resistance in which case good and useful ideas (innovations and technologies) are not embraced and adopted by indigenous communities due to lack of ownership.

Despite the resistance, indigenous populations have, nevertheless, managed to survive for centuries adapting in many different ways to adverse climate conditions and managing to create sustainable livelihood systems. Diverse forms of knowledge, deeply rooted in their relationships with the environment as well as in cultural cohesion, have allowed many indigenous communities to maintain a sustainable use and management of natural resources, to protect their environment and to enhance their resilience. Their ability to observe, adapt and mitigate has helped many indigenous communities face new and complex circumstances that have often severely impacted their way of living and their territories. Indigenous knowledge and climate resilient agricultural practices/technologies which are cost effective lead to food security at household level as they can easily be carried out by resource poor or small farmers. This demonstrates that indigenous languages and knowledge have a role to play in sustainable agriculture.

It is therefore crucial to demonstrate and promote both foreign and local practices and technologies in the local communities. These demonstrations, their dissemination and their replication by the farmers will serve as evidences for informed advocacy. On the basis of these evidences, the target group will advocate that these practices be promoted by government in its plans and programs. This is because research has shown that when local people and their local knowledge is left out of the planning and policy making process, the results are that any development issue is either less successful or, in some cases, disastrous [29, 30].

\section{Indigenous Languages and Sustainable Agriculture}

It is through language that we communicate with the world, define our identity, express our history and culture, learn, defend our human rights and participate in all aspects of society. Through language, people preserve their community's history, customs and traditions, memory, unique modes of thinking, meaning and expression. People also use language to construct their future. Language is, also, a vehicle of thought and the expression of culture. It expresses a people's way of life, their perception of things and their world view. This embodies their ideals and innovations which embrace respects for technological and scientific innovations [1]. In this sense, science and technology can be acquired and better understood through the indigenous languages. This concerns the background knowledge of language as a vehicle of communication within any society especially in a multi-lingual set up like Kenya.

Agriculture remains the basis of life for most citizens in Kenya. However, growth in the agricultural sector has been slow. The majority of those in agricultural production are illiterates who can only use their indigenous languages [31, 32]. Taken from the above therefore, it can be argued that at its most elementary level, the use of indigenous languages for our farmers can ensure a flow of information on fertilizers, pesticides, high yield variety of crops, appropriate planting seasons, irrigation and preservation as well as marketing outlets. This would be made easier by employing the local languages in agricultural education and extension services which transform new agro-technologies to the rural farmers with a view to increasing their yields, income and enhancing their standard of living, as these are the languages which the rural people understand, practice and evolve in their everyday lives. There is no denying the fact that when farmers are talked to in their languages; it becomes easier for both the facilitator and the farmers themselves. The point is that the intention of using indigenous languages in agricultural economy is to achieve meaningful transmission of ideas, alter wrong beliefs and taboos while assimilation of positive values and norms can be favorably promoted among the locals.

The emphasis given to the use of indigenous languages in pursuance of growth and development in agriculture, cannot be ignored because using foreign languages, does not only defeat the main aim of mass participation in the sector but also limits the advantages accruing from foreign industry and investment to a privileged urban elite [33] who do not participate in agricultural production. Therefore, if Kenya must improve agricultural production she needs to transmit the 
foreign ideas, concepts and technology, which would undoubtedly be transmitted in a foreign language, to the farmers in the language that they understand. It is only after this happens that the nation can move towards advancement in agro-technology.

To make the agricultural sector of the economy attractive, both national and county governments have a role to play by letting the government's programs reach the grassroots. And how this can be made possible is by encouraging the use of indigenous languages for proper dissemination of information on those programs to local farmers. Any policies and programs on innovations and technologies introduced that do not factor in indigenous languages towards their implementation will remain dormant, with little impact in the sector. [34] suggests that a large number of sub-professional personnel like field instructors and extension workers who are willing to take up this task should be people who are closer to the farmers and know their fauna and flora, people who understand the norms and folklores of these farmers. This would go a long way in making instruction, facilitation, motivation and above all communication easy and effective.

Indigenous languages would help, in different ways to attain sustainable agriculture. First, indigenous languages and knowledge can be used to facilitate communication in rural agricultural programmes. Communication between agricultural personnel and farmers, in Kenya, is often very poor. Communication in the agricultural sector in Kenya has a structure that favours literacy, top-down message flows and innovations developed elsewhere. This often results in a serious comprehension gap. Often incompatibility of an innovation with local cultural values results in either slow or no adoption, with the later taking precedence over the former. Local languages will, therefore, go a long way in facilitating communication by providing a better understanding of how local people perceive their environment and organise their perceptions. The aim of this is to overcome the tendency to impose an outsider's structure upon a local situation by explaining why things are being done from the perspective of the local people.

Second, indigenous languages can help in integrating the art and knowledge developed by farmers over the centuries with the advances of modern science and incorporating new technology and innovations into existing knowledge. This can be achieved by presenting the new innovations and technologies in a way that assures the farmer that such innovations and technologies would satisfy some currently desired production need. The only way to do this in order to convince the local people is by using their local languages.

Third, indigenous languages can help in disseminating new innovation and technologies in agriculture to the rural masses. The benefits of new developments in agriculture have not reached the vast majority of the rural poor. The scope has, generally, been biased by formally educated, urban-based people, and has usually operated in their favour. In cases where improving the quality of rural agricultural production has been the aim of agricultural programmes and policies, rural people have been virtually uninvolved in the design. Again, in most cases the ecological and socio-economic conditions of the target area have not been compatible with the innovations and technologies in which case the desired results have never been achieved on a sustained basis. By dismissing indigenous languages and knowledge as irrelevant, rural people result to adopting practices that they deem best while ignoring what would be good practice. This quite often leads to undesirable effects of inappropriate use of local resources and wasted expense of time and money involved in developing and extending the innovations and technologies. Indigenous languages can facilitate the participation of rural people in improved agricultural activities with the overall aim of enabling the achievement of a closer fit between intended technical solutions and existing social frameworks.

Fourth, indigenous languages will enable change from within. Many indigenous innovations and technologies are environmentally friendly. They can, thus, provide useful insights for modern research and extension. Indigenous technological innovations often represent the most appropriate adaptations to the environmental and cultural conditions of the societies which create them. Some innovations can be borrowed, almost intact, from indigenous knowledge based in other cultures. In addition, new innovations and technologies can be localised and then incorporated into existing indigenous ones. Such are susceptible to adoption as they are hard to resist for the fact that they are not entirely foreign, but meant to improve traditional techniques, using cheap hand tools and simple labour-saving devices.

\section{The Model}

To incorporate indigenous languages into the agricultural process for sustainable agriculture, indigenous languages, indigenous knowledge, culture beliefs, attitudes and taboos of a given people must be considered in all stages in the process. The integration be in all of the following stages: the conception of the new innovations and technologies in agriculture; the formulation of policies and programs on the same; the dissemination of the innovations, technologies, policies and programs; the people residing in a particular geographical location that need to implement them and in the implementation process itself. Dissemination, which is key, could utilise extension officers, media (both oral and print), training and communication units in all the agricultural facilities in the nation. All these should present the information using relevant indigenous languages. The geographical location of the people to implement the innovations and technologies should be considered as well as het vary from one community to the other. And each community has its unique language, culture and knowledge. Implementation should involve demonstrations and replication of the same to a large population. The model as proposed in this study is shown in figure 1 below. 


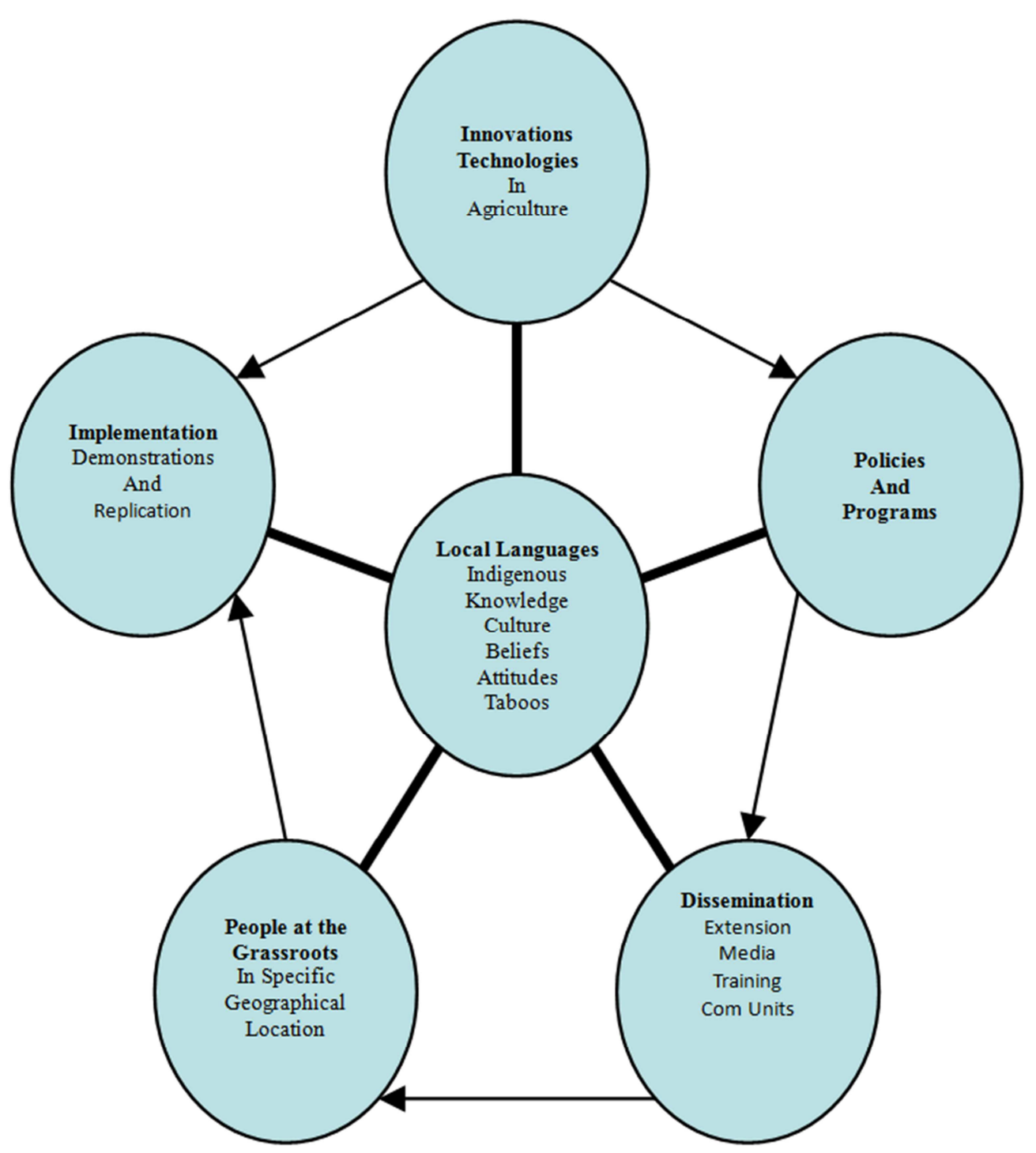

Figure 1. The Indigenous Language Model for Innovation and Technology Transfer in Agriculture.

\section{Conclusion}

For sustainable agriculture, leading to food security, to be achieved in Kenya, the integration of indigenous languages at all stages in the agricultural process is inevitable. Indigenous languages should be used in the conception of new innovations and technologies in agriculture through translators. Policies and programmes developed with regard to new innovations and technologies in agriculture should also use indigenous languages. The innovations, technologies, formulated policies and programs should be disseminated to the people to implement them, who are the rural folks. Indigenous languages should be used in all modes of dissemination including but not limited to media, training, extension officers, communication units, demonstrations etc. in order to achieve this, county and national governments in Kenya must embrace the integration of indigenous languages into agricultural production for sustainability by setting aside money in the budget for the same.

\section{References}

[1] Ishima, J. L. J. (2004). Indigenous Languages and Technological Development: Issues and Perspectives. In: Language, Literature, Education and Democracy in Nigeria, 23-27.

[2] Altbach, P. G. (1999). The Dilemma of Publishing in African Languages: A Comparative Perspective. In P. G. Altbach \& D. Teferra (Eds.). Publishing in African Languages: Challenges and Prospects. Bellagio Studies in Publishing 10, 1-10. Chestnut Hill, MA: Bellagio Publishing Network.

[3] Kembo-Sure. (1991). Language Functions and Language Attitudes in Kenya. English World Wide Language and Communication. Cambridge: MIT Press.

[4] Ogechi, N. (2001). Publishing in Kiswahili and Indigenous Languages for Enhanced Adult Literacy in Kenya. Afrikanistische Arbeitspapiere 68 (2001)-Swahili Forum 3, 185-199. 
[5] Stanton, N. (2009). Mastering Communication. Palgrave: Macmillan. Technology Policy Studies Network. University Press.

[6] Antel, J. M. \& McGuckin, T. (1993). Technological Innovation, Agricultural Productivity and Environmental Quality. In G. A. Carlson, D. Zilberman and J. Miranowski (Eds.). Agricultural and Environmental Resource Economics, 175-220. New York, NY: Oxford University Press.

[7] Evenson, R. E. (2001). Economic Impacts of Agricultural Research and Extension. In B. L. Gardner and G. Rausser (Eds.). Handbook of Agricultural Economics, 574-628. New York, NY: Elsevier Science.

[8] Falck-Zepeda, J. B., Traxler, G. \& Nelson, R. G. (2000). Surplus Distribution from the Introduction of a Biotechnology Innovation. American Journal of Agricultural Economics, 82 (2), 360-369.

[9] Safakish, M. (2015). The Role of Indigenous Knowledge in Sustainable Rural Economic Development. Journal of Applied Environmental and Biological, 5 (9), 285-289.

[10] Sharland, L. (1991). Awareness of Farm Women on Environmental Degradation due to Use of Some Selected Modern Agricultural Technologies. M. S. (Ag. Ext. Ed.) Thesis, Department of Agricultural Extension Education, Bangladesh Agricultural University, Mymensingh.

[11] Brun, J. P. (2010). Missing Pieces: 7 Ways to Improve Employee Well-Being and Organizational Effectiveness. New York: Palgrave Macmillan.

[12] Summers, D. C. (2010). Quality Management: Creating and Sustaining Organizational Effectiveness. Upper Saddle River: Prentice Hall.

[13] Lutgen-Sandvik, P. (2010). Destructive Organizational Communication: Processes, Consequences, and Constructive Ways of Organizing. New York: Routledge.

[14] Ondondo, E. A. (2014). Effects of Communication Impairments on Knowledge Acquisition. Us-China Foreign Language, 24 (10), 805-813.

[15] Fasold, R. (1992). The Sociolinguistics of Society. Oxford: Blackwell.

[16] Wardhaugh, R. (1992). An Introduction to Sociolinguistics. Oxford: Blackwell.

[17] Akmajian, A., Demers, R., Farmer, A., \& Harnish, R. (2010). Linguistics: An Introduction to Language and Communication. Cambridge, Mass: MIT Press.

[18] Lunenburg, F. C. (2010). Communication: The Process, Barriers, And Improving Effectiveness. Schooling, 1 (1), 1-11.

[19] Chomsky, N. (1986). Knowledge of Language. Cambridge: MIT Press.
[20] Crystal, D. (2010). The Cambridge Encyclopedia of Language. Cambridge: Cambridge.

[21] Fromkin, V. R., \& Hyams, N. (2010). An Introduction to Language. Boston: Thomson-Henle.

[22] Lyons, J. (1992). Language and Linguistics: An Introduction. Cambridge: Cambridge University.

[23] Yule, G. (2000). The Study of Language. Cambridge: Cambridge University Press.

[24] Cashman, K. (1987). Seeing the Forest for the Trees. Paper presented at the Farming Systems Research Symposium, "How Systems Work". University of Arkansas, Fayetteville, Arkansas.

[25] Warren, D. M. (1976). Indigenous Knowledge Systems for Activating Local Decision-Making Groups in Rural Development. In: G. Chu et al. (Eds.). Communications for Group Transformation in Development, 307-329. Communications Monograph No. 2. The East West Center, Honolulu.

[26] Warren, D. M. (1988). Linking Scientific and Indigenous Agricultural Systems. In: J. Lin Compton (Ed.). The Transformation of International Agricultural Research and Development. Westview Press (in press), Boulder.

[27] Bell, M. (1979). The Exploitation of Indigenous Knowledge or the Indigenous Exploitation of Knowledge: Whose Use of What for What? IDS Bulletin 10, 44-50.

[28] Brokensha, D., Warren, D. M. \& Werner, O. (1980). Indigenous Knowledge Systems and Development. University Press of America, Lanham, MD.

[29] Grenier, L. (1998). Working with Indigenous Knowledge: A Guide for Researchers. International Development Research Centre (IDRC).

[30] Ty, H. X. \& Cuc, L. T. (1998). Indigenous Knowledge of the Vietnam Uplanders in Agriculture and Natural Resources Management. Hanoi: Agriculture Publishing House (In Vietnamese).

[31] Geekie, R. (1995). Mali: Championing Women's Literacy Programme. African Farmer- A Publication of the Hunger Project 15, 34-50.

[32] Okonkwo, C. E. (1983). Mother Tongue Education: A Reminder of some Forgotten Views to Nigerian Education; Journal of Research in Curriculum 1, 69-80.

[33] Bamgbose, A. (1991). Language and the Nation: The Language Question in Sub-Saharan Africa. Edinburgh University Press, Great Britain.

[34] Adesina, L. O. (2015). Indigenous Languages as Tools for Effective Communication of Science and Technology for Food Production in Nigeria. Theory and Practice in Language Studies 5 (3), 463-468. 